\title{
Biological and physiological properties of reverse ankyrin engineered for dimer construction to enhance HIV-1 capsid interaction
}

\author{
On-anong Juntit ${ }^{1}$, Umpa Yasamut ${ }^{1}$, Supachai Sakkhachornphop ${ }^{2}$, Koollawat Chupradit ${ }^{1}$, \\ Weeraya Thongkum ${ }^{1}$, Tanchanok Wisitponchai ${ }^{1}$, Panchika Prangkio ${ }^{3}$, Chatchawan \\ Srisawat ${ }^{4}$, Vannajan Lee ${ }^{5}$, Tawan Chokepaichitkool ${ }^{6}$, Prachya Kongtawelert ${ }^{6}$, Piyarat \\ Nimmanpipug ${ }^{3}$, and Chatchai Tayapiwatana ${ }^{1}$ \\ ${ }^{1}$ Chiang Mai University Faculty of Associated Medical Sciences \\ ${ }^{2}$ Chiang Mai University Research Institute for Health Sciences \\ ${ }^{3}$ Chiang Mai University Faculty of Science \\ ${ }^{4}$ Mahidol University Faculty of Medicine Siriraj Hospital \\ ${ }^{5}$ Universiti Malaya Fakulti Sains \\ ${ }^{6}$ Chiang Mai University Faculty of Medicine
}

October 15, 2021

\begin{abstract}
Assembly and budding in the late-stage of human immunodeficiency virus type 1 (HIV-1) production relies on the polymerization of Gag protein at the inner leaflet of the plasma membrane. We previously generated an ankyrin repeat protein (Ank1D4) that specifically interacts with the CAp24 protein. This study aimed to improve the binding activity of Ank1D4 by generating two platforms for the Ank1D4 dimer. The design of these constructs featured a distinct orientation of monomeric Ank1D4 connected by a linker peptide $\left(\mathrm{G}_{4} \mathrm{~S}\right)_{4}$. The binding surfaces in either dimer generated from the C-terminus of the Ank1D4 monomer linked with the N-terminus of another monomer (Ank1D4 $\mathrm{NC}-\mathrm{NC}$ ) or its inverted form (Ank1D4 $\mathrm{NC}-\mathrm{CN}$ ), similar to monomeric Ank1D4. The interaction of Ank1D4 NC-CN with CAp24 from capture ELISA was significantly greater than that of Ank1D4 NC-NC and the parental Ank1D4. The bifunctional characteristic of Ank1D4 NC-CN was further demonstrated using sandwich ELISA. The binding kinetics of these ankyrins were evaluated using bio-layer interferometry analysis. The $\mathrm{K}_{\mathrm{D}}$ of Ank1D4 NC-CN, Ank1D4 NC-NC and monomeric Ank1D4 was $3.5 \mathrm{nM}, 53.7 \mathrm{nM}$, and $126.2 \mathrm{nM}$, respectively. The dynamics of the interdomain linker and the behavior of ankyrin dimers were investigated in silico. Upon the binding distance calculation from the candidate structures, the achievement in obtaining double active sites is more possible in Ank1D4 NC-CN. The CD spectroscopic data indicated that secondary structure of dimer forms resemble Ank1D4 monomer $\alpha$-helical content. This finding confers the strategy to generate dimer from rigid scaffold for acquiring the binding avidity.
\end{abstract}

\section{Hosted file}

Bifunctional ankyrin with sequence inversion.doc available at https://authorea.com/users/ 441324/articles/541848-biological-and-physiological-properties-of-reverse-ankyrinengineered-for-dimer-construction-to-enhance-hiv-1-capsid-interaction 
A.

pQE30-Ank1D4 NC-NC
\begin{tabular}{|c|c|c|c|c|c|}
\hline T5 promoter \\
\hline
\end{tabular}

B.

pQE30-Ank1D4 ${ }_{\mathrm{NC}-\mathrm{CN}}$

\begin{tabular}{|c|c|c|c|c|c|c|}
\hline \multicolumn{6}{|c|}{ RBS ATG } & \multirow[b]{2}{*}{ AmpR } \\
\hline T5 promoter & $\begin{array}{c}6 \mathrm{6X} \\
\text { HIS }\end{array}$ & Ank1D4 NC & $\begin{array}{l}\text { Linker } \\
\left(\mathrm{G}_{4} \mathrm{~S}\right) 4\end{array}$ & Ank1D4 CN & $\mathrm{CmR}$ & \\
\hline
\end{tabular}
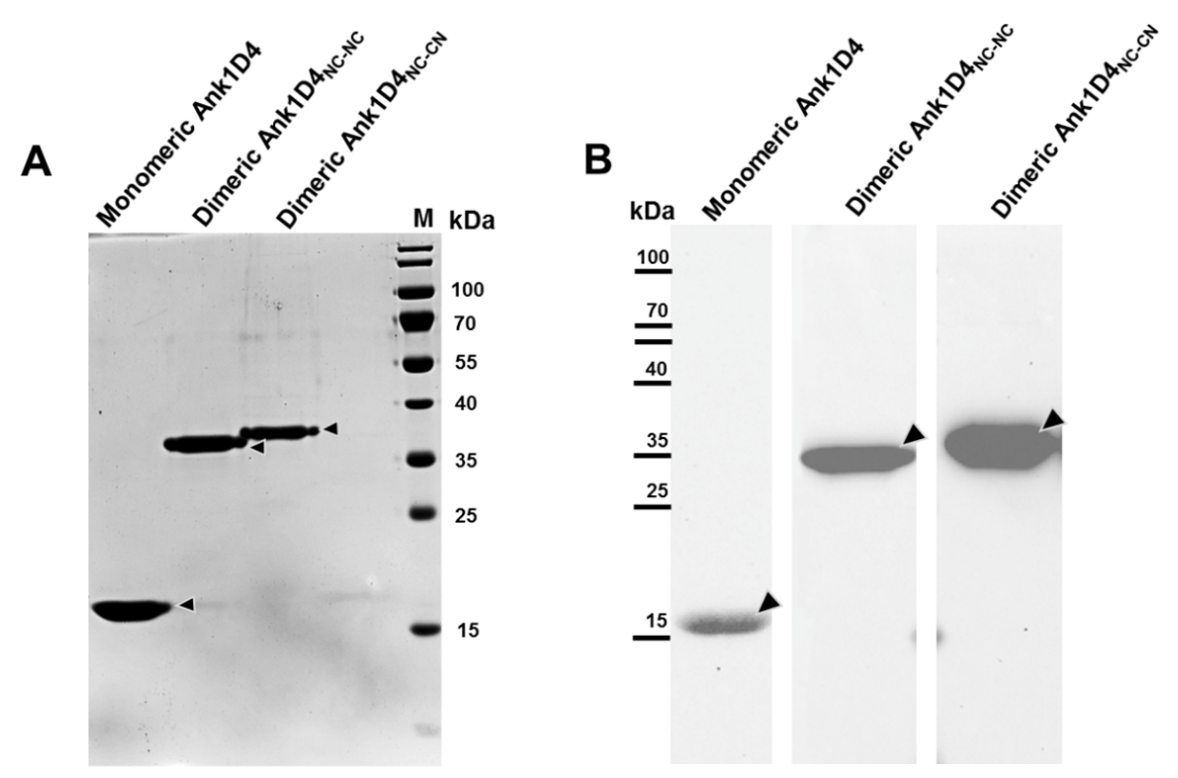


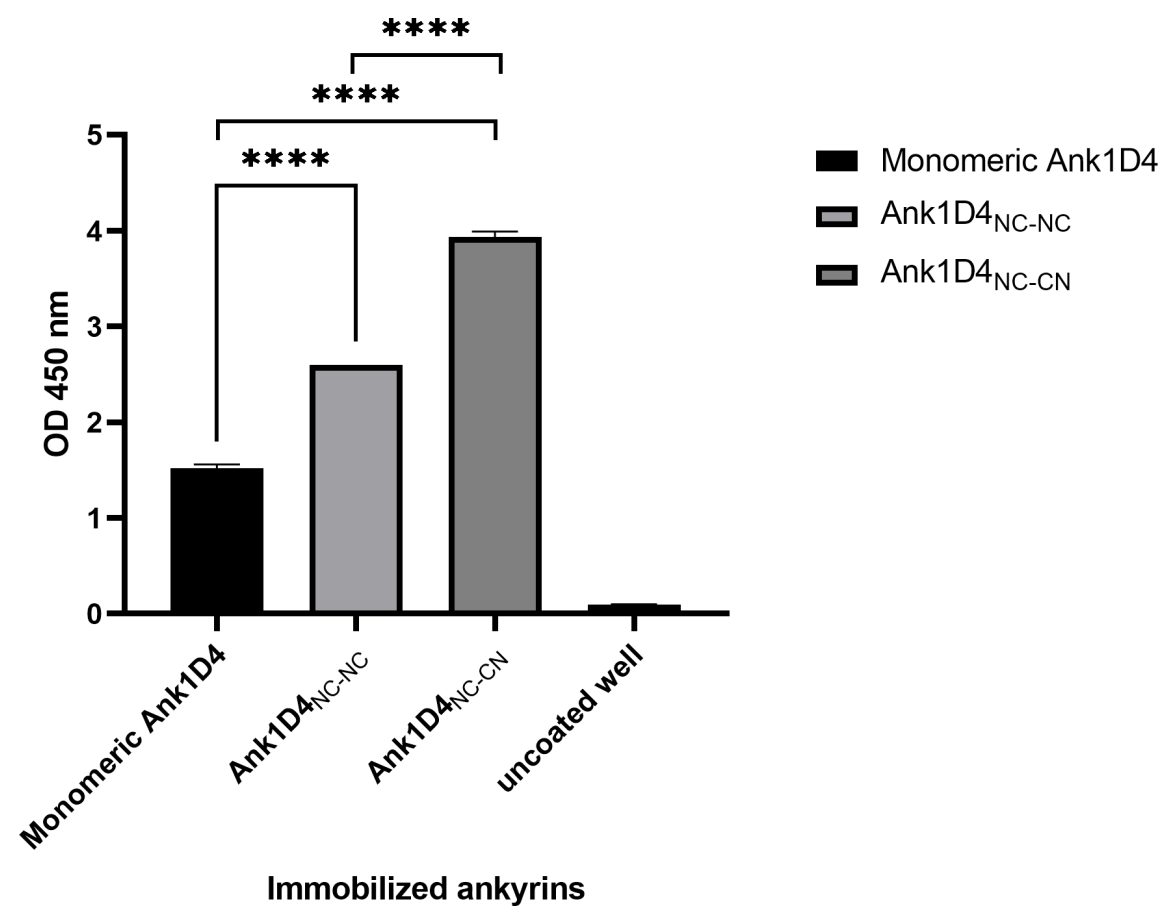


A

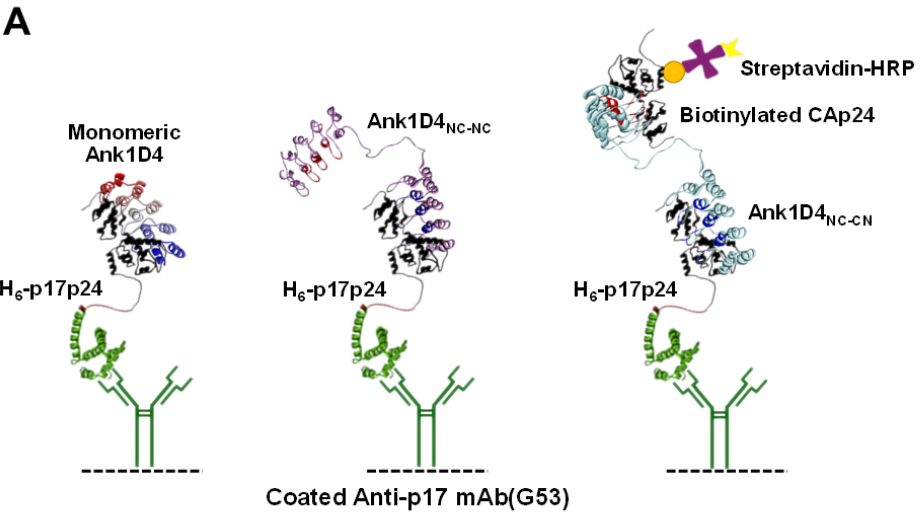

B

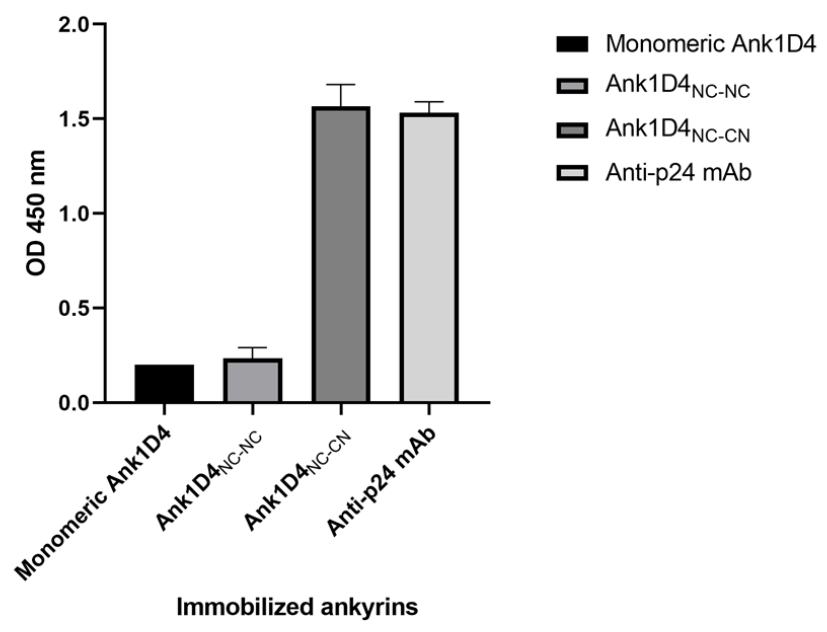


A

\begin{tabular}{lccc}
\hline \multicolumn{1}{c}{ Variants } & Kon $(\mathbf{1} / \mathbf{M s})$ & Koff $\left._{\text {of }} \mathbf{s}\right)$ & $\mathrm{K}_{\mathrm{D}}(\mathrm{nM})$ \\
\hline Monomeric Ank1D4 & $2.1 \times 10^{5}$ & $2.7 \times 10^{-2}$ & $126.2 \pm 3.6$ \\
Dimeric Ank1D4NC-NC & $1.9 \times 10^{5}$ & $1.0 \times 10^{-2}$ & $53.7 \pm 5.0$ \\
Dimeric Ank1D4 & $5.8 \times 10^{4}-\mathrm{CN}$ & $1.5 \times 10^{-4}$ & $3.5 \pm 2.9$ \\
\hline
\end{tabular}

B

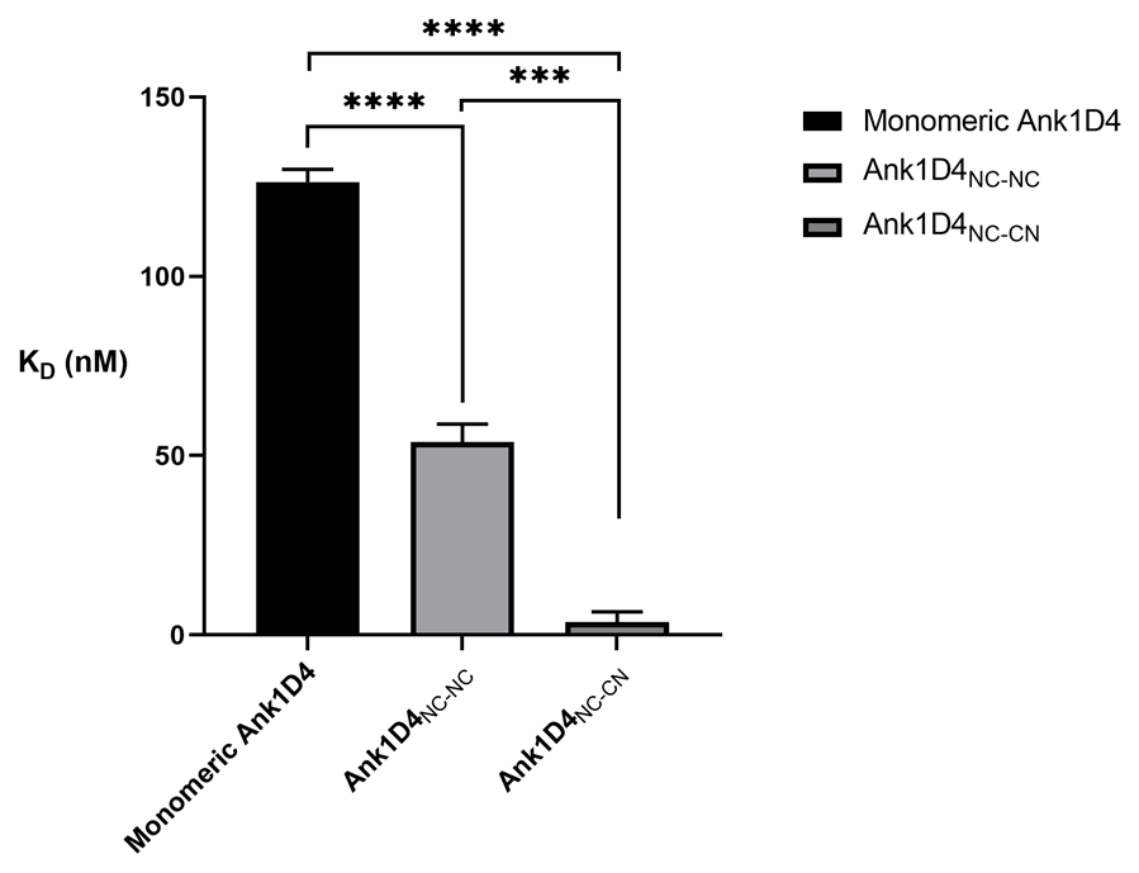


A

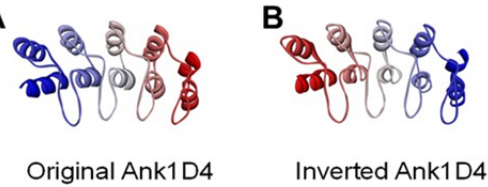

Original Ank1D4

D

LLQGGGGSGGGGSGGGGSGGGGSTSDI
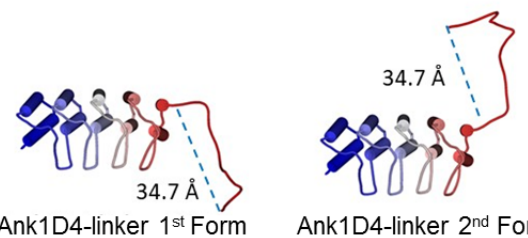

Ank1D4-linker $2^{\text {nd }}$ Form

F
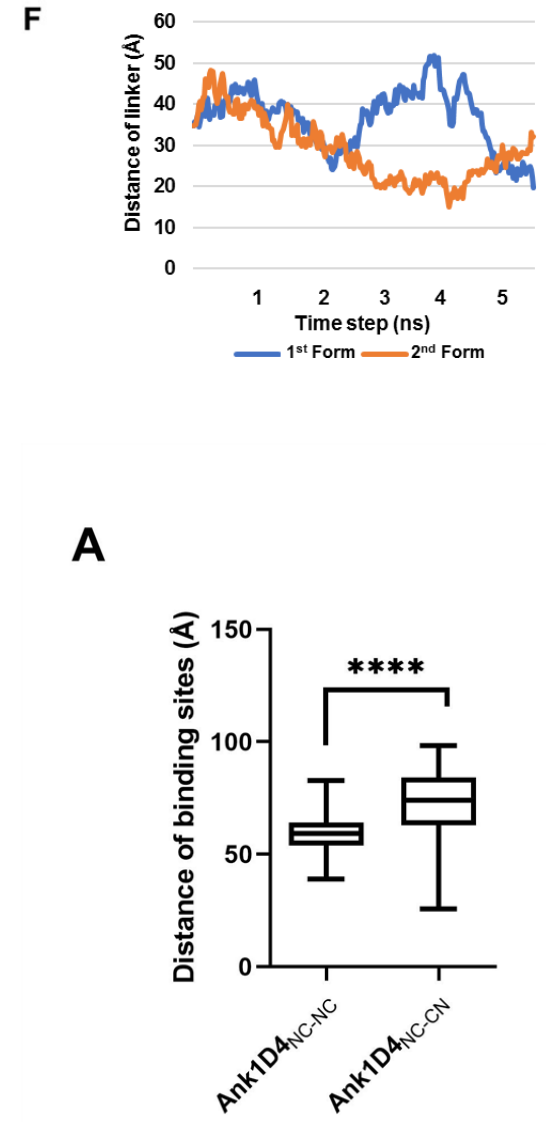

Ank1D4-linker $1^{\text {st }}$ Form

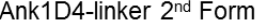

C

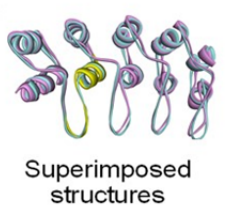
structures

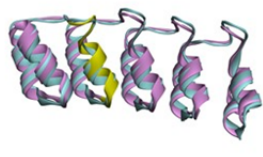

A

B

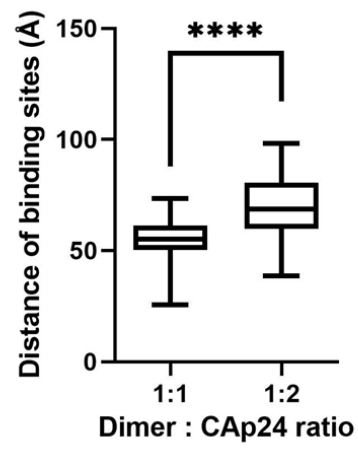


A
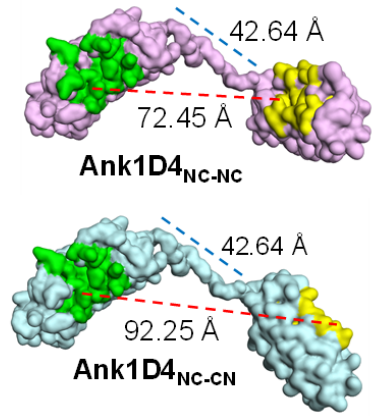

E

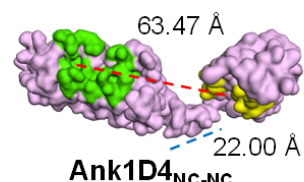

G

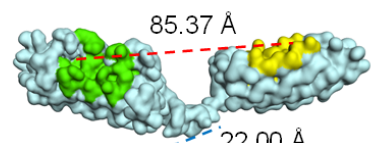

Ank1D4 ${ }_{\text {NC-CN }}$

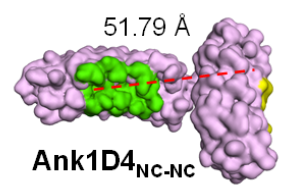

K

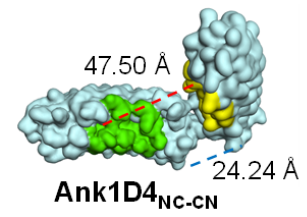

B

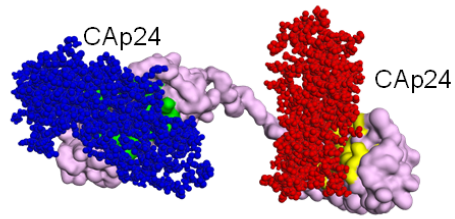

D

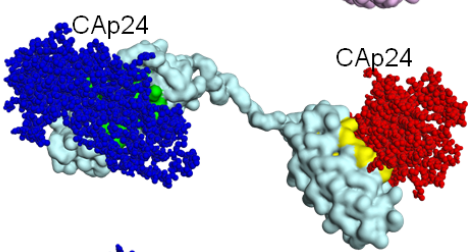

F

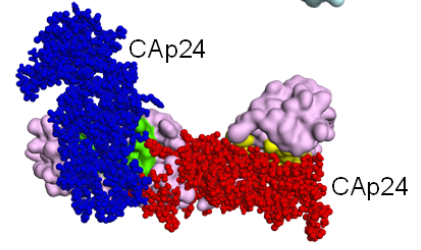

H

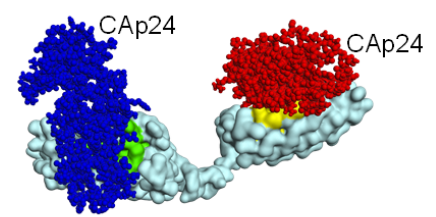

J

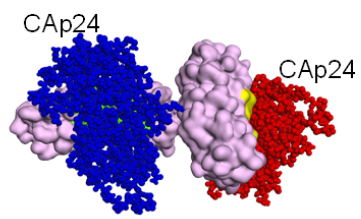

L

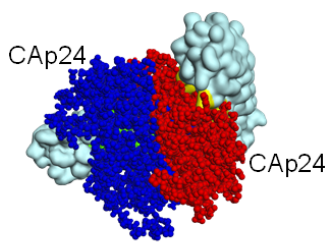

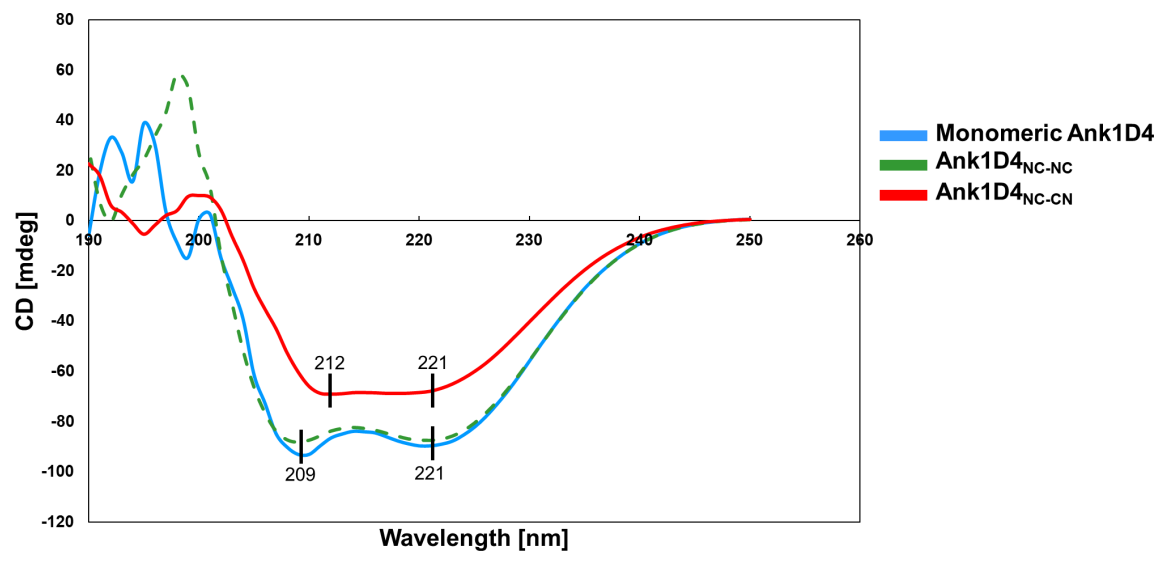

